\title{
Genistein inhibits proliferation of colon cancer cells by attenuating a negative effect of epidermal growth factor on tumor suppressor $\mathrm{FOXO} 3$ activity
}

\author{
Wentao Qi ${ }^{1}$, Christopher R Weber ${ }^{2^{*}}$, Kaarin Wasland ${ }^{1}$ and Suzana D Savkovic ${ }^{1 *}$
}

\begin{abstract}
Background: Soy consumption is associated with a lower incidence of colon cancer which is believed to be mediated by one of its of components, genistein. Genistein may inhibit cancer progression by inducing apoptosis or inhibiting proliferation, but mechanisms are not well understood. Epidermal growth factor (EGF)-induced proliferation of colon cancer cells plays an important role in colon cancer progression and is mediated by loss of tumor suppressor $\mathrm{FOXO} 3$ activity. The aim of this study was to assess if genistein exerts anti-proliferative properties by attenuating the negative effect of EGF on $\mathrm{FOXO}$ activity.

Methods: The effect of genistein on proliferation stimulated by EGF-mediated loss of FOXO3 was examined in human colonic cancer HT-29 cells. EGF-induced FOXO3 phosphorylation and translocation were assessed in the presence of genistein. EGF-mediated loss of $\mathrm{FOXO} 3$ interactions with p53 (co-immunoprecipitation) and promoter of p27kip1 (ChIP assay) were examined in presence of genistein in cells with mutated p53 (HT-29) and wild type p53 (HCT116). Silencing of p53 determined activity of FOXO3 when it is bound to p53.

Results: Genistein inhibited EGF-induced proliferation, while favoring dephosphorylation and nuclear retention of FOXO3 (active state) in colon cancer cells. Upstream of FOXO3, genistein acts via the PI3K/Akt pathway to inhibit EGF-stimulated FOXO3 phosphorylation (i.e. favors active state). Downstream, EGF-induced disassociation of FOXO3 from mutated tumor suppressor p53, but not wild type p53, is inhibited by genistein favoring FOXO3-p53(mut) interactions with the promoter of the cell cycle inhibitor p27kip1 in colon cancer cells. Thus, the FOXO3-p53(mut) complex leads to elevated p27kip1 expression and promotes cell cycle arrest.
\end{abstract}

Conclusion: These novel anti-proliferative mechanisms of genistein suggest a possible role of combining genistein with other chemoreceptive agents for the treatment of colon cancer.

Keywords: Genistein, EGF, FOXO3, proliferation, colon cancer

\section{Background}

Soy consumption is associated with a lower incidence of cancer in Asian countries [1,2]. Although these epidemiological studies are correlative, it has been hypothesized that soy compounds may have anti-cancer properties. Indeed numerous studies have shown a prominent component of soy, genistein, has anticancer

\footnotetext{
* Correspondence: Christopher.Weber@uchospitals.edu;

SSavkovic@northshore.org

'Department of Medicine, Division of Gastroenterology; NorthShore

University Research Institute, Evanston, IL 60201, USA

2Department of Pathology, The University of Chicago; Chicago, IL 60637,

USA

Full list of author information is available at the end of the article
}

properties [3-5], and the mechanism whereby genistein exerts anticancer effects has been the subject of considerable interest.

It has been shown that a synthetic analogue of the genistein, phenoxodiol, significantly reduced colonic tumor growth through inhibitory effects on the immune system [6]. Genistein effectively suppresses the growth of colon cancer cells [7] by attenuating activity of the PI3K/Akt pathway [7-9], which is known to be critical in the regulation of colon cancer progression [10,11]. Additionally, genistein affects the Wnt signaling pathway in colon cancer cells, which is known to be important to colon tumorigenesis [12] by inducing Wnt5a expression 
[13]. Finally, a recent study demonstrated that in colon cancer cells genistein affect the expression of estrogen receptor and some tumor suppressor genes $[14,15]$ supporting a role of membrane receptors and tumor suppressors in antiproliferative effects of genistein.

In human colon cancer EGF receptor (EGFR) expression and activity are increased [16,17], and targeting this receptor has played an increasing therapeutic role [18]. We have demonstrated that proliferation of colon cancer cells, stimulated with signals from EGFR, is mediated by loss of tumor suppressor FOXO3 activity [19]. EGF attenuates FOXO3 activity via the PI3K/Akt pathway and results in loss of cell cycle arrest and enhanced proliferation [19]. When activate (dephopshorylated), FOXO3 is localized in the nucleus and binds to DNA or other transcriptional factors regulating the expression of specific target genes involved in control of cell cycle progression, the mitotic program, or induction of apoptosis [20]. The effect of genistein on EGF-mediated loss of FOXO3 activity and associated colon cell proliferation has not been determined. We hypothesize that anti-proliferative properties of genistein in colon cancer cells are mediated by inhibition of the negative effect of EGF on FOXO3 activity, thus promoting cell cycle arrest.

This study demonstrates a new anti-proliferative mechanism of genistein mediated by inhibiting the negative effect of EGF on tumor suppressor FOXO3, which favors the interaction of FOXO3 with mutated p53 in colon cancer cells. The FOXO3-p53(mut) complex binds to the promoter of p27kip1, causing increased p27kip1 expression and subsequent induction of cell cycle arrest in colon cancer cells. This is a novel antiproliferative mechanism and is relevant to designing novel therapeutic agents, analogous to genistein, which may be used to treat colon cancer.

\section{Methods}

\section{Cell Culture}

HT-29 colon cancer cells (American Type Culture Collection (ATCC), Manassas, VA), carrying mutation in tumor suppressor p53, and HCT116, with wild type p53, were grown in McCoy's 5A medium (Sigma-Aldrich, Saint Louis, MO) containing $10 \%$ FBS (Gibco) at $37^{\circ} \mathrm{C}$ and $5 \% \mathrm{CO}_{2}$. Monolayers were kept in McCoy's $5 \mathrm{~A}$ media without serum for 20-24 h before experiments.

\section{Treatment}

To examine the effects of genistein on proliferation, cells were incubated with 10-150 $\mu \mathrm{M}$ genistein (LC Laboratories, Woburn, MA) for 48 hours. To examine the effects of genistein on induced FOXO3 phosphorylation, translocation, interaction with $\mathrm{p} 53$, and binding to p27kip1 promoter, monolayers were treated with EGF
(100 ng/ml) (Sigma-Aldrich) with and without mild concentration of genistein $(50 \mu \mathrm{M})$ for 48 hours [21,22]. During EGF and genistein treatment, cells were placed in serum-free and antibiotic-free medium.

\section{Immunofluorescent Staining}

To determine the inhibitory effect of genistein on EGFinduced FOXO3 translocation from the nucleus to the cytosol immunofluorescent staining was performed. Monolayers were fixed with $3.7 \%$ paraformaldehyde and permeabilized with $0.2 \%$ Triton X-100. For staining, anti-FOXO3 primary antibody (Cell Signaling, Danvers, MA) and Alexa 488 conjugated secondary antibody were used (Molecular Probes-Invitrogen, Carlsbad, CA), as previously described $[19,23,24]$. After washing with PBS, coverslips were mounted using Prolong Gold antifade reagent (Molecular Probes), and images were captured with a Nikon Confocal Microscope C1 and analyzed with EZ-C1 software (Nikon, Tokyo, Japan).

\section{Protein Extraction}

Total protein was extracted using a lysis buffer (Cell Signaling, Danvers, MA) with a protease inhibitor cocktail (Sigma-Aldrich), and protein concentration was determined by Bradford assay (Bio-Rad, Hercules, CA). The protein extracts were stored at $-20^{\circ} \mathrm{C}$ until further processing.

\section{Immunoblot}

Equal amounts of protein $(40 \mu \mathrm{g})$ were separated by SDS-PAGE and transferred to nitrocellulose membranes by voltage gradient transfer (Bio-Rad). Prepared blots were blocked and detection was performed using specific antibodies for total FOXO3 (Cell Signaling Technology, Danvers, MA), phosphorylated FOXO3 at Thr 32 (Upstate Biotechnology), pAkt (Cell Signaling), p27kip1 (Cell Signaling), actin, EGFR, pEGFR, and p53 (Santa Cruz Biotechnology, Santa Cruz, CA). After washing, the blots were incubated with horseradish peroxidase linked secondary antibodies (Cell Signaling, Danvers, MA), and detection was achieved with ECL plus western blotting detection reagents (GE Healthcare, Buckinghamshire, United Kingdom). Intensity of the bands was quantified by optical densitometry using Labworks 4.6 Image Acquisition and Analysis Software (UVP, Cambridge, UK), and was calculated as percentage of changes relative to control.

\section{Co-Immunoprecipitation}

The effect of genistein on FOXO3-p53 incitation was assessed by co-immunoprecipitation. One milligram of whole cell lysate was incubated with $10 \mu \mathrm{g}$ of mouse anti-FOXO3 antibody (Cell Signaling) and protein A beads overnight at $4^{\circ} \mathrm{C}$. Immunoprecipitates were 
washed five times with lysis buffer, separated by SDSPAGE, and transferred to membranes. Immunoblot analysis was performed with anti-p53 antibody from rabbit (Santa Cruz Biotechnology) to prevent cross-reaction. IgG antibody from mouse was used as a negative control.

\section{Chromatin Immunoprecipitation (ChIP) Assay}

The effect of genistein on FOXO3 binding to p27kip1 promoter was examined by ChIP assay according to the manufacturer's instructions (Millipore, Temecula, CA). After cross-linking with $1 \%$ formaldehyde, the cells were incubated in lysis buffer and sonicated to cut DNA (200 to $1000 \mathrm{bp})$. Aliquots $(20 \mu \mathrm{l})$ from each sample were held separately for use as "input DNA" in PCR analysis. Equal amounts of protein were incubated with $\mathrm{FOXO} 3$ (Cell Signaling) or p53 (Santa Cruz) antibodies at $4{ }^{\circ} \mathrm{C}$ overnight, and the complexes comprised of DNA-protein were pelleted with protein G-agarose. After reversing the immunoprecipitated complexes and input aliquots with $5 \mathrm{M} \mathrm{NaCl}$ at $65^{\circ} \mathrm{C}$ for 4 hours, protein was separated from DNA using proteinase K. Extracted DNA (phenol/chloroform) was amplified using primers from p27kip1 promoter (forward: 5'-GTC CCT TCC AGC TGT CAC AT-3'; reverse, 5'-GGA AAC CAA CCT TCC GTT CT-3'). Input represents PCR amplification of DNA from cell lysate before immunoprecipitation with the primers used to amplify the p27kip1 promoter and $\beta$-actin (forward, 5'-CCA CAC TGT GCC CAT CTA CG-3'; reverse, 5'- AGG ATC TTC ATG AGG TAG TCA GTC AG-3').

\section{Cell Proliferation Assays}

An inhibitory effect of genistein on proliferation of colon cancer cell lines was detected using the MTS assay (Promega; Medison, WI). Cells grown in regular media were plated on 96-well plates (5000 cells per well) and after 48 hours of incubation with the experimental compounds, part of the medium was removed, and MTS solution was added for another 3 hours at $37^{\circ}$ C. A water-soluble formazan product converts from MTS and was detected at $490 \mathrm{~nm}$ using a SPECTRAmax Plus Microplate Reader (Molecular Devices, Sunnyvale, CA). Results obtained at $490 \mathrm{~nm}$ were converted to percentile changes relative to control.

\section{SiRNA}

Silencing p53 (siRNA) was utilized to determine its effect on FOXO3 activity in HT-29 cells. Cells were transfected with p53 siRNA (Santa Cruz Biotechnology) (GCAUGAACCGGAGGCCCAU) or negative-control (Invitrogen) using Lipofectamine RNAiMAX (Invitrogen). After 5 hours, transfection media was replaced with regular media containing genistein and protein was extracted 48 hours later.

\section{Statistical Analysis}

Data were compared by a one-way analysis of variance and a Student's $t$ test. The results are expressed as means \pm standard deviation. Differences were considered significant at $\mathrm{p}<0.05$.

\section{Results}

Genistein inhibits EGF-induced proliferation, $\mathrm{FOXO} 3$ phosphorylation, and translocation in colon cancer cells EGF promotes proliferation and is known to be critical to the progression of colon cancer [16-18]. Anti-proliferative properties of genistein, exerted by targeting different kinases of various proliferative pathways [9,25-28] were assessed on EGF-induced proliferation in colon cancer cells. EGF-induced proliferation of HT-29 cells was inhibited by genistein (Figure 1A), suggesting that genistein may affect the EGF pathway in colon cancer cells. We previously demonstrated that EGF-induced proliferation is mediated via loss of tumor suppressor FOXO3 activity [19]. In the presence of genistein, EGFinduced FOXO3 phosphorylation at Thr32 (inactivation) [19] was inhibited (Figure 1B), showing that genistein promotes FOXO3 activity. Active FOXO3 localizes to the nucleus and following phosphorylation by EGF, FOXO3 translocates to the cytosol [19]. Genistein inhibited EGF-induced FOXO3 translocation to the cytosol, and thus FOXO3 remained in the nucleus (Figure 1C). Moreover, the high basal level of phosphorylated FOXO3 (inactive) in sub-confluent HT-29 cells was significantly diminished by genistein (Figure 1D), further supporting that genistein promotes FOXO3 activity in proliferative colon cancer cells regardless of EGF stimulation. These data suggested that attenuation of EGFinduced proliferation by genistein is in part mediated by inhibition of FOXO3 phosphorylation (inactivation) and translocation to the cytosol in colon cancer cells (i.e. FOXO3 inactivation).

\section{Genistein inhibition of EGF-induced FOXO3 phosphorylation is mediated by the PI3K/Akt pathway}

The above data show that genistein inhibits EGFinduced FOXO3 phosphorylation at Thr32, which is known to be a PI3K/Akt specific site [19]. Since PI3K/ Akt is downstream of EGFR, we sought to examine whether genistein targets the EGFR or the PI3K/Akt pathway. Although genistein modestly increases basal pEGFR (at Ser1070), it did not affect expression and phosphorylation of the EGFR during EGF treatment (Figure 2A). Additionally, an EGF-induced 4-fold increase in Akt phosphorylation was diminished by genistein (Figure 2B). Also, genistein insignificantly decreased the basal level of pAkt. Thus we speculate genistein inhibits EGF-induced FOXO3 phosphorylation via the PI3K/Akt pathway. 


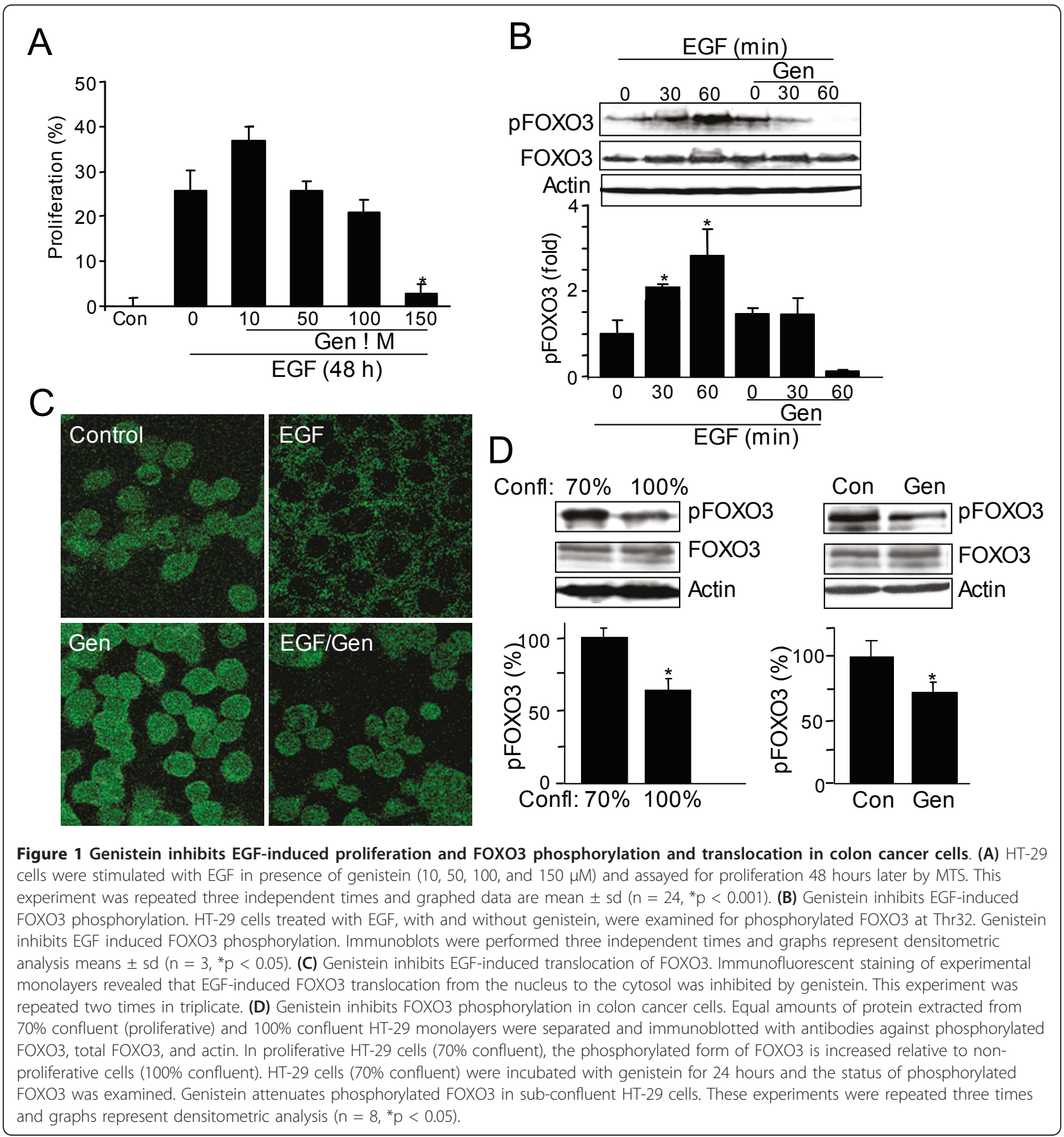

Genistein inhibits EGF-induced FOXO3 disassociation from the promoter of p27kip1 cell cycle inhibitor

Downstream, EGF treatment led to FOXO3 disassociation from the promoter for the cell cycle inhibitor p27kip1 [19]. Thus we assessed if genistein inhibits proliferation by preventing EGF-induced FOXO3 disassociation from p27kip1 promoter. In HT-29 cells genistein increased p27kip1 expression 2-fold (Figure 3A) and
ChIP assay revealed that genistein inhibits EGF-induced FOXO3 disassociation from p27kip1 promoter (Figure $3 \mathrm{~B})$. Thus, we speculate that genistein promotes FOXO3 binding to the p27kip1 promoter, increasing p27kip1 expression, and ultimately leading to cell cycle arrest in colon cancer cells. Next, we sought to determine the mechanism whereby genistein promotes FOXO3 binding to the p27kip1 promoter. 


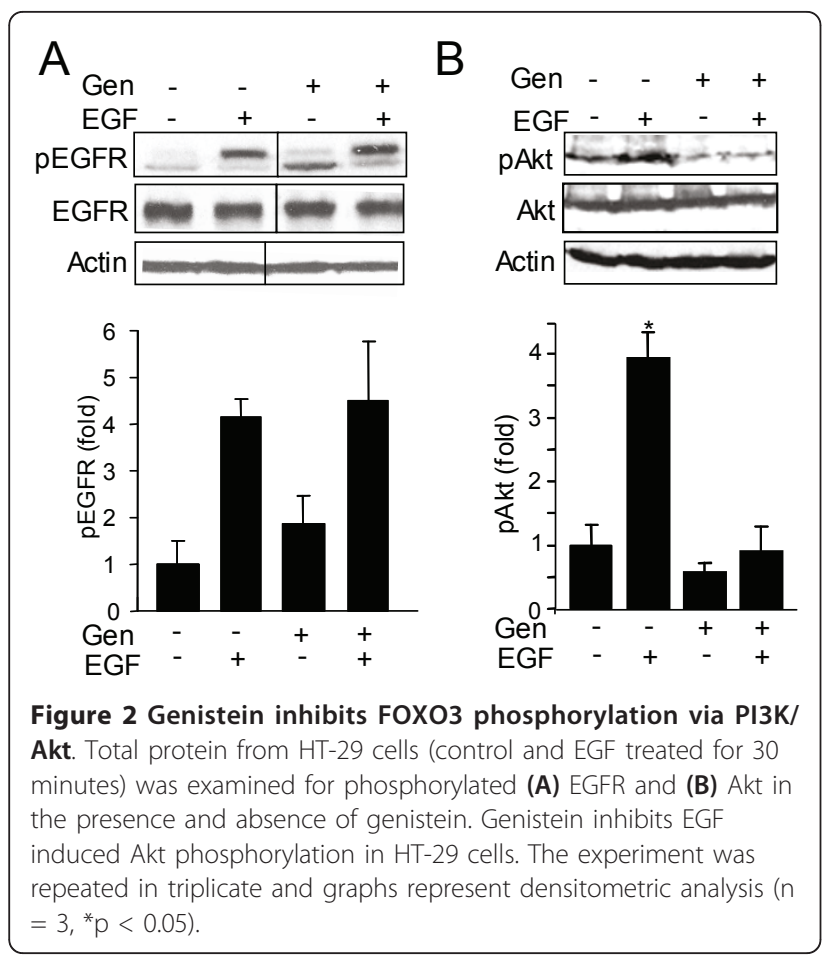

Genistein inhibits EGF-mediated disassociation of FOXO3 from p53(mut) tumor suppressor

Transcriptional activity of FOXO3 could be modulated though interactions with other transcriptional factors such as tumor suppressor p53 [29], which is known to be mutated in some colonic cancers and is critical to cancer progression [30-33]. We assessed if genistein affects interactions of FOXO3 with mutated p53, thus further affecting FOXO3 activity. Genistein increases expression of mutated p53 by 2.5-fold in HT-29 cells (Figure 4A), and co-immunoprecipitation demonstrated an increased interaction of p53(mut) with FOXO3 (Figure 4B). Moreover, co-immunoprecipitation shows that the FOXO3p53(mut) complex is diminished during EGF treatment, while genistein reduces the effect of EGF (Figure $4 \mathrm{C}$ ). Next, we assessed if FOXO3-p53 interactions are specific for mutated p53 using colonic HCT116 cells with wild type p53. In HCT116 cells, although FOXO3-p53 complex was found, EGF and genistein did not affect this interaction (Figure 4D), supporting that the interaction of FOXO3 with mutated p53 is targeted by genistein. Taken together these data show that the interaction between p53 and FOXO3, which is impaired by EGF, is promoted by genistein in HT-29 cells.

\section{Genistein mediated FOXO3 and p53(mut) interaction} promotes FOXO3 activity on p27kip1 promoter

The above data support that genistein increases FOXO3 binding to the p27kip1 promoter and also favors

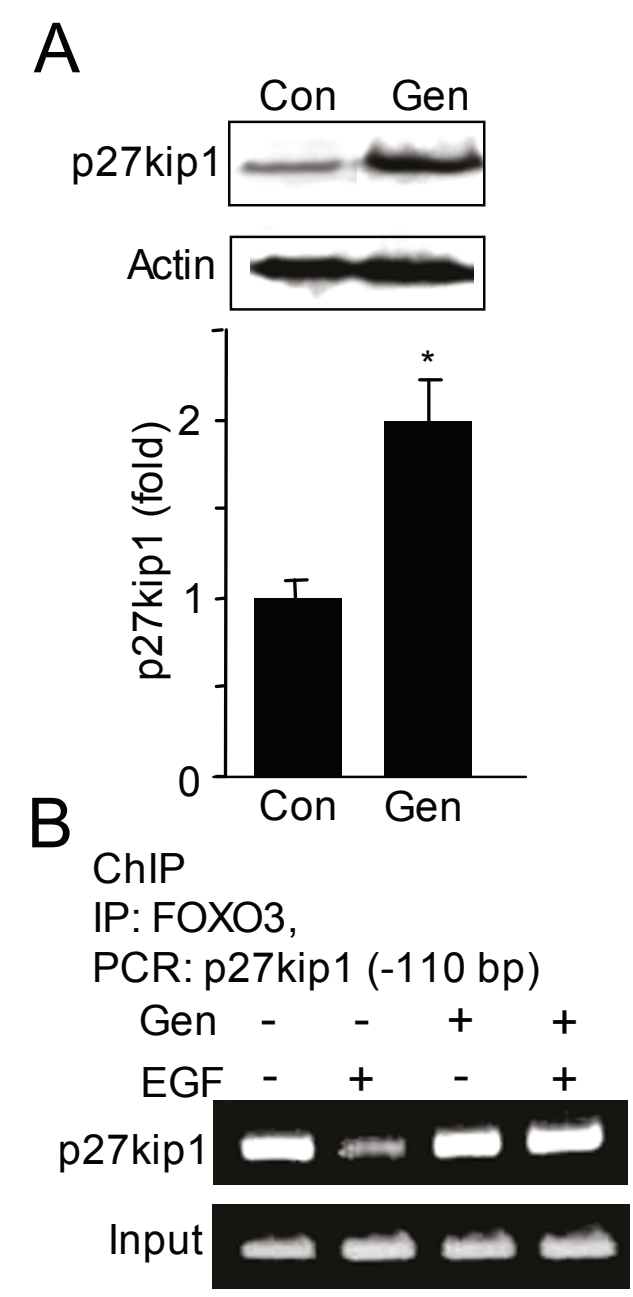

Figure 3 Genistein increases p27kip1 expression and promotes FOXO3 binding to the p27kip1 promoter. (A) Protein from control and genistein treated HT-29 cells was separated and immunoblotted for p27kip1. Immunoblots revealed that genistein increased p27kip1. The experiment was performed three independent times and quantified using densitometry $(n=3$, * $p<$ 0.05). (B) Genistein inhibits FOXO3 disassociation from p27kip1 promoter. ChIP assay was performed to determine $\mathrm{FOXO} 3$ binding to p27kip1 promoter (-110 bp). EGF-induced FOXO3 disassociation from p27kip1 promoter (-110 bp) was inhibited by genistein. Input represents PCR amplification of DNA from cell lysate prior to immunoprecipitation with the primers from p27kip1 promoter. This experiment was repeated two times.

FOXO3 interactions with p53(mut). However, the p27kip1 promoter did not show putative p53 binding sites (GGACATGCCCGGGCATGTCC) [34,35] in the $-200 \mathrm{bp}$ regions where the FOXO3 binding site is located $(-110 \mathrm{bp})$. Thus, we hypothesized that the FOXO3-p53(mut) complex could be found on the FOXO3 binding site of p27kip1 promoter. Using ChIP assay, performed by immunoprecitating protein-DNA complex with anti-p53 antibody, p53 was found to be 


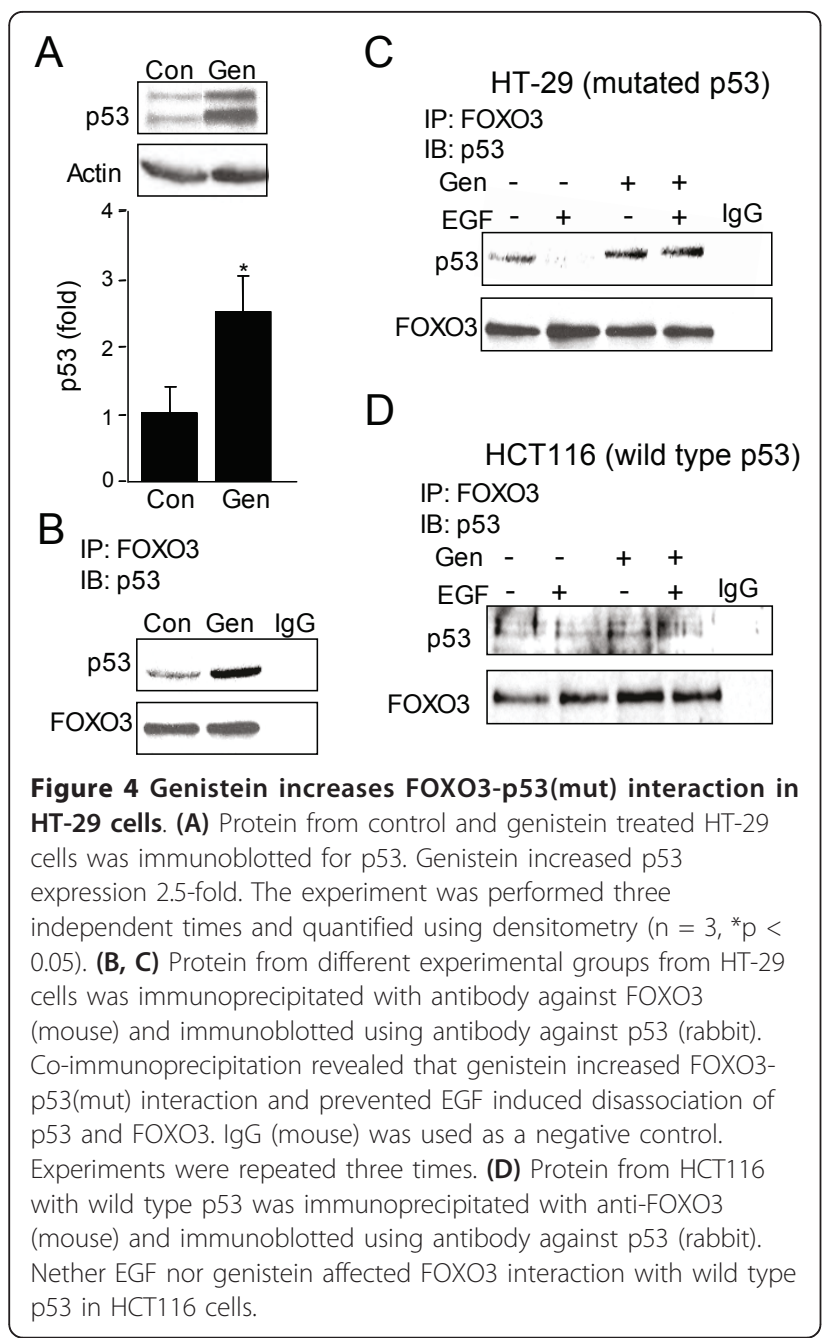

present in the p27kip1 promoter within the FOXO3 binding region (Figure 5A). In HT-29 cells with silent $\mathrm{p} 53$, genistein did not increase p27kip1 expression (Figure 5B), supporting that p53(mut) positively regulates FOXO3 activity in the FOXO3-p53(mut) complex. The genistein-stimulated interaction between p53 and FOXO3 promotes FOXO3 activity and resistance to EGF, thus increasing expression of the p27kip1 cell cycle inhibitor (Figure 6).

\section{Discussion}

Genistein, a predominant component of soy products, has been shown to have anti-cancer properties $[2,3,5]$. This study revealed a novel mechanism that genistein utilizes to inhibit proliferation. Proliferation of EGF treated colon cancer cells is mediated by loss of FOXO3 activity [19], and here we showed this pathway to be inhibited by genistein. Upstream, genistein inhibits EGF induced loss of FOXO3 activity by targeting the PI3K/ Akt pathway. Downstream, genistein inhibits EGF-
A

$$
\begin{aligned}
& \text { ChIP } \\
& \text { IP: p53 } \\
& \text { PCR: p27kip1 (-110 bp) }
\end{aligned}
$$
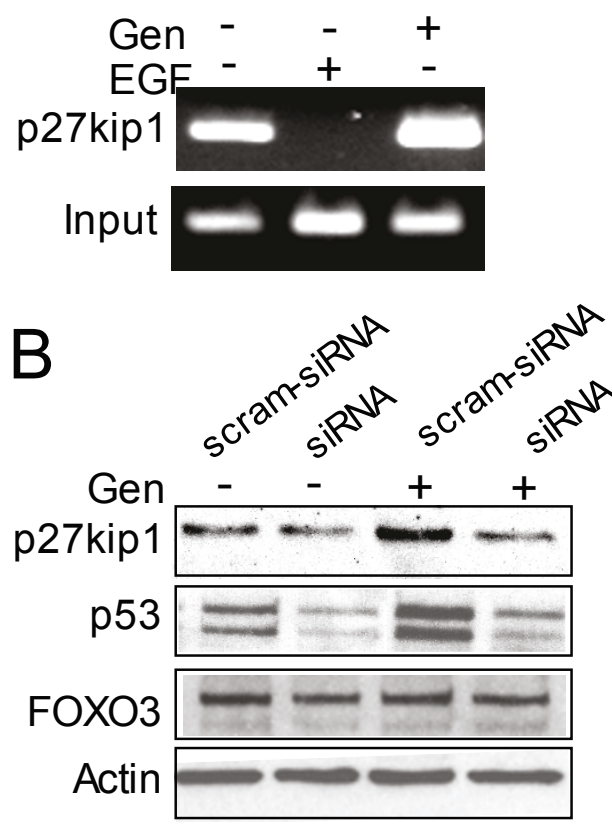

Figure 5 The FOX03-p53(mut) complex promotes p27kip1 expression. (A) The protein-DNA complex was immunoprecipitated with antibody against p53 and DNA was amplified by conventional PCR with primers from the p27kip1 promoter region (ChIP assay) with input representing PCR amplification from lysate before immunoprecipitation with the same primers. The FOXO3-p53(mut) complex is bound to the p27kip1 promoter. (B) HT-29 cells transfected with p53 siRNA or scramble siRNA were treated with genistein and examined for p27kip1 by immunoblot. Silencing of p53 attenuates genistein-induced p27kip1 expression. These experiments were repeated two independent times.

induced FOXO3 disassociation from p53(mut), which further promotes FOXO3 activity and leads to increased expression of the p27kip1 cell cycle inhibitor, which inhibits proliferation in colon cancer cells.

We demonstrated that one of the anti-proliferative mechanisms of genistein in colon cancer cells is to promote FOXO3 activity by inhibiting EGF-induced FOXO3 phosphorylation (inactivation) via the PI3K/Akt pathway. Active FOXO3 negatively regulates proliferation of colon cancer cells [36], and we showed that its inactivation is an essential step in EGF-mediated proliferation [19]. Although some studies demonstrated that high concentrations of genistein can downregulate EGFR in prostate cells [37], we showed that the concentration of genistein used for this study did not affect EGFR expression in colon cancer cells and had modest 


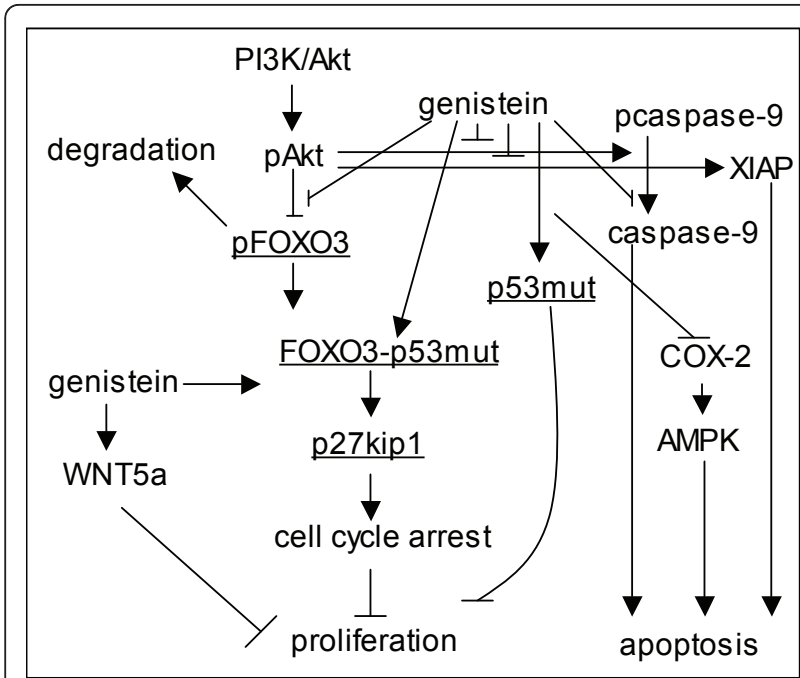

Figure 6 Genistein inhibits proliferation in colon cancer cells by promoting FOXO3 activity. Schematic representation of pathways targeted by genistein in colon cancer cells $[7-9,13,21,50]$. Genistein promotes FOXO3 activity by inhibiting PI3K/Akt and stimulating FOXO3 interaction with p53. Downstream, genisteinmediated FOXO3 activity increases p27kip1 expression, which promotes cell cycle arrest and leads to inhibition of proliferation.

effects on activation of EGFR that are most likely nonspecific. It has been shown that genistein inhibits EGFstimulated serine, threonine, and tyrosine phosphorylation [38]. Also, genistein affects estrogen receptors [39], which are critical in colon cancer progression [14]. Therefore, we speculate, that genistein inhibit Akt independently of EGFR, by attenuating either kinase activity downstream of EGFR or blocking estrogen receptor. It has been previously demonstrated that genistein inhibits proliferation in colon cancer cells via PI3K/Akt [40], a pathway known to be critical to colon cancer progression $[10,11,41]$, however downstream mechanisms were not well understood. This study demonstrated that genistein inhibits PI3K/Akt activation that leads to prevention of FOXO3 phosphorylation (inactivation) in colon cancer cells and revealed a new mechanism whereby genistein attenuates proliferation of colon cancer cells.

Active FOXO3 attenuates proliferation by upregulation of the cell cycle inhibitor p27kip1 [36,42], and we showed that EGF-induced FOXO3 disassociation from the p27kip1 promoter [19] is inhibited by genistein in colon cancer cells. In prostate and breast cancer cells, the anti-proliferative effects of genistein occur by increasing levels of the cell cycle inhibitor p27kip1 $[43,44]$, but upstream mechanisms were not understood. Here we showed that genistein increases p27kip1 expression in colon cancer cells by promoting FOXO3 binding to the p27kip1 promoter. It is important to take into account that increased p27kip1 by genistein is most likely one of the mechanisms of inhibition of proliferation and that the other targeted molecules also play a role. Also, this study demonstrated that for increased p27kip1 expression, interaction between FOXO3 and mutated tumor suppressor p53 is required. In contrast to human lung cancer cells where genistein increased wild type but not mutated p53 [45], in colon cancer HT-29 cells we showed that genistein increased expression of mutated p53. Although, wild type p53 interacts with FOXO3 thereby decreasing its activity in the FOXO3-53 complex $[29,46,47]$, this study demonstrated that mutated p53 increased FOXO3 activity in HT-29 cells. Additionally EGF treatment did not affect interactions between wild type p53 and FOXO3 further supporting that a mutation of p53 is most likely accountable for the genistein effect. Since a mutation of p53 is critical to colon cancer development [30-33], the antiproliferative properties of genistein may relate to targeting mutated p53 and thus promoting FOXO3 activity and cell cycle arrest.

This study showed that genistein inhibits proliferation of colon cancer cells by attenuating a negative effect of EGF on tumor suppressor FOXO3 activity, thereby promoting FOXO3 interaction with mutated p53, which leads to expression of p27kip1 and cell cycle arrest. These findings support a potential role of genistein in combination with other chemopreventive agents $[3,48,49]$ for the treatment of colon cancer.

\section{Conclusion}

Genistein inhibits EGF-induced proliferation in colon cancer cells by promoting FOXO3 activity, targeting upstream the PI3K/Akt pathway, and stimulating downstream FOXO3 interaction with tumor suppressor p53mut. As a result of increased FOXO3 activity, expression of p27kip1 is elevated, which leads to cell cycle arrest. This is a new anti-proliferative mechanism for genistein and sets the foundation for the potential combined use of genistein with other chemoreceptive agents in the treatment of colon cancer.

\section{Acknowledgements}

We thank Drs. Hemant Roy and Ramesh Wali for helpful assistance in preparing the manuscript. This work was supported in part by a Senior Investigator Award from the Crohn's and Colitis Foundation of America (CCFA\#1953), a NorthShore University Healthsystem and University of Chicago Collaborative grant.

\section{Author details}

'Department of Medicine, Division of Gastroenterology; NorthShore University Research Institute, Evanston, IL 60201, USA. 'Department of Pathology, The University of Chicago; Chicago, IL 60637, USA.

\section{Authors' contributions}

QW: Carried out and design the experiments, and participated in the preparation of figures. CW: Designed hypothesizes and participated in the preparation of the manuscript. KW: Performed initial studies finding this 
mechanism. SS: Envisioned the study, participated in its design, coordination and final manuscript preparation. All authors read and approved the final manuscript.

\section{Competing interests}

The authors declare that they have no competing interests.

Received: 5 February 2011 Accepted: 3 June 2011

Published: 3 June 2011

\section{References}

1. Adlercreutz CH, Goldin BR, Gorbach SL, Hockerstedt KA, Watanabe S, Hamalainen EK, Markkanen MH, Makela TH, Wahala KT, Adlercreutz T: Soybean phytoestrogen intake and cancer risk. The Journal of Nutrition 1995, 125(3 Suppl):757S-770S.

2. Park OJ, Surh YJ: Chemopreventive potential of epigallocatechin gallate and genistein: evidence from epidemiological and laboratory studies. Toxicology Letters 2004, 150(1):43-56.

3. Wang HK: The therapeutic potential of flavonoids. Expert Opinion on Investigational Drugs 2000, 9(9):2103-2119.

4. Barnes S, Peterson TG: Biochemical targets of the isoflavone genistein in tumor cell lines. Proceedings of the Society for Experimental Biology and Medicine Society for Experimental Biology and Medicine (New York, NY 1995, 208(1):103-108.

5. Sarkar FH, Li Y: Soy isoflavones and cancer prevention. Cancer Investigation 2003, 21(5):744-757.

6. Georgaki S, Skopeliti M, Tsiatas M, Nicolaou KA, loannou K, Husband A, Bamias A, Dimopoulos MA, Constantinou Al, Tsitsilonis OE: Phenoxodiol, an anticancer isoflavene, induces immunomodulatory effects in vitro and in vivo. Journal of Cellular and Molecular Medicine 2009 13(9B):3929-3938.

7. Zhu Q, Meisinger J, Van Thiel DH, Zhang Y, Mobarhan S: Effects of soybean extract on morphology and survival of Caco-2, SW620, and HT-29 cells. Nutrition and Cancer 2002, 42(1):131-140.

8. Chodon D, Ramamurty N, Sakthisekaran D: Preliminary studies on induction of apoptosis by genistein on HepG2 cell line. Toxicol In Vitro 2007, 21(5):887-891.

9. Su SJ, Chow NH, Kung ML, Hung TC, Chang KL: Effects of soy isoflavones on apoptosis induction and G2-M arrest in human hepatoma cells involvement of caspase- 3 activation, $\mathrm{BCl}-2$ and $\mathrm{BCl}-\mathrm{XL}$ downregulation, and Cdc2 kinase activity. Nutrition and Cancer 2003, 45(1):113-123.

10. Cantley LC: The phosphoinositide 3-kinase pathway. Science (New York, NY 2002, 296(5573):1655-1657.

11. Samuels $\mathrm{Y}$, Ericson K: Oncogenic PI3K and its role in cancer. Current Opinion in Oncology 2006, 18(1):77-82.

12. Takahashi M, Wakabayashi K: Gene mutations and altered gene expression in azoxymethane-induced colon carcinogenesis in rodents. Cancer Science 2004, 95(6):475-480.

13. Wang $\mathrm{Z}$, Chen $\mathrm{H}$ : Genistein increases gene expression by demethylation of WNT5a promoter in colon cancer cell line SW1116. Anticancer Research 2010, 30(11):4537-4545.

14. Bielecki A, Roberts J, Mehta R, Raju J: Estrogen receptor-beta mediates the inhibition of DLD-1 human colon adenocarcinoma cells by soy isoflavones. Nutrition and Cancer 2011, 63(1):139-150.

15. Berner C, Aumuller E, Gnauck A, Nestelberger M, Just A, Haslberger AG: Epigenetic control of estrogen receptor expression and tumor suppressor genes is modulated by bioactive food compounds. Annals of Nutrition \& Metabolism 2011, 57(3-4):183-189.

16. Rego RL, Foster NR, Smyrk TC, Le M, O'Connell MJ, Sargent DJ, Windschitl $H$, Sinicrope FA: Prognostic effect of activated EGFR expression in human colon carcinomas: comparison with EGFR status. British Journal of Cancer 2010, 102(1):165-172.

17. Fichera A, Little N, Jagadeeswaran S, Dougherty U, Sehdev A, Mustafi R, Cerda S, Yuan W, Khare S, Tretiakova M, Gong C, Tallerico M, Cohen G, Joseph L, Hart J, Turner JR, Bissonnette M: Epidermal growth factor receptor signaling is required for microadenoma formation in the mouse azoxymethane model of colonic carcinogenesis. Cancer Research 2007, 67(2):827-835.

18. Modjtahedi H, Essapen S: Epidermal growth factor receptor inhibitors in cancer treatment: advances, challenges and opportunities. Anti-cancer Drugs 2009, 20(10):851-855.
19. Qi W, Weber CR, Wasland K, Roy H, Wali R, Joshi S, Savkovic SD: Tumor suppressor $\mathrm{FOXO} 3$ mediates signals from the EGF receptor to regulate proliferation of colonic cells. American Journal of Physiology Gastrointestinal and Liver Physiology 2011, 300(2):G264-272.

20. Burgering BM, Kops GJ: Cell cycle and death control: long live Forkheads. Trends Biochemical Science 2002, 27(7):352-360.

21. Nakamura Y, Yogosawa S, Izutani Y, Watanabe H, Otsuji E, Sakai T: A combination of indol-3-carbinol and genistein synergistically induces apoptosis in human colon cancer HT-29 cells by inhibiting Akt phosphorylation and progression of autophagy. Molecular Cancer 2009, 8:100.

22. YU Z, Li W, LiU F: Inhibition of proliferation and induction of apoptosis by genistein in colon cancer HT-29 cells. Cancer Letters 2004, 215(2):159-166.

23. Snoeks L, Weber CR, Turner JR, Bhattacharyya M, Wasland K, Savkovic SD: Tumor suppressor Foxo3a is involved in the regulation of lipopolysaccharide-induced interleukin-8 in intestinal HT-29 cells. Infection and Immunity 2008, 76(10):4677-4685.

24. Snoeks L, Weber CR, Wasland K, Turner JR, Vainder C, Qi W, Savkovic SD: Tumor suppressor $\mathrm{FOXO} 3$ participates in the regulation of intestinal inflammation. Laboratory Investigation 2009, 89(9):1053-1062.

25. Duffy C, Perez K, Partridge A: Implications of phytoestrogen intake for breast cancer. CA: A Cancer Journal for Clinicians 2007, 57(5):260-277.

26. Kikuno N, Shiina H, Urakami S, Kawamoto K, Hirata H, Tanaka Y, Majid S, Igawa M, Dahiya R: Genistein mediated histone acetylation and demethylation activates tumor suppressor genes in prostate cancer cells. International Journal of Cancer 2008, 123(3):552-560.

27. Majid S, Kikuno N, Nelles J, Noonan E, Tanaka Y, Kawamoto K, Hirata H, Li LC, Zhao H, Okino ST, Place RF, Pookot D, Dahiya R: Genistein induces the p21WAF1/CIP1 and p16INK4a tumor suppressor genes in prostate cancer cells by epigenetic mechanisms involving active chromatin modification. Cancer Research 2008, 68(8):2736-2744.

28. Lian F, Li Y, Bhuiyan M, Sarkar FH: p53-independent apoptosis induced by genistein in lung cancer cells. Nutrition and Cancer 1999, 33(2):125-131.

29. Wang F, Marshall CB, Yamamoto K, Li GY, Plevin MJ, You H, Mak TW, Ikura M: Biochemical and structural characterization of an intramolecular interaction in FOXO3a and its binding with p53. Journal of Molecular Biology 2008, 384(3):590-603.

30. Rodrigues NR, Rowan A, Smith ME, Kerr IB, Bodmer WF, Gannon JV Lane DP: p53 mutations in colorectal cancer. Proceedings of the National Academy of Sciences of the United States of America 1990, 87(19):7555-7559.

31. Rand A, Glenn KS, Alvares CP, White MB, Thibodeau SM, Karnes WE Jr: p53 functional loss in a colon cancer cell line with two missense mutations (218leu and 248trp) on separate alleles. Cancer Letters 1996, 98(2):183-191.

32. Jaiswal AS, Narayan S: p53-dependent transcriptional regulation of the APC promoter in colon cancer cells treated with DNA alkylating agents. The Journal of Biological Chemistry 2001, 276(21):18193-18199.

33. Gerdes H: Colon cancer and the p53 oncogene. Gastroenterology 1991, 100(3):842-843.

34. Funk WD, Pak DT, Karas RH, Wright WE, Shay JW: A transcriptionally active DNA-binding site for human p53 protein complexes. Molecular and Cellular Biology 1992, 12(6):2866-2871.

35. Kwon TK, Nagel JE, Buchholz MA, Nordin AA: Characterization of the murine cyclin-dependent kinase inhibitor gene p27Kip1. Gene 1996 180(1-2):113-120.

36. Dijkers PF, Medema RH, Pals C, Banerji L, Thomas NS, Lam EW, Burgering BM, Raaijmakers JA, Lammers JW, Koenderman L, Coffer PJ: Forkhead transcription factor FKHR-L1 modulates cytokine-dependent transcriptional regulation of p27(KIP1). Molecular and Cellular Biology 2000, 20(24):9138-9148.

37. Dalu A, Haskell JF, Coward L, Lamartiniere CA: Genistein, a component of soy, inhibits the expression of the EGF and ErbB2/Neu receptors in the rat dorsolateral prostate. The Prostate 1998, 37(1):36-43.

38. Akiyama $\mathrm{T}$, Ishida J, Nakagawa $\mathrm{S}$, Ogawara H, Watanabe $\mathrm{S}$, Itoh $\mathrm{N}$, Shibuya M, Fukami Y: Genistein, a specific inhibitor of tyrosine-specific protein kinases. The Journal of Biological Chemistry 1987, 262(12):5592-5595.

39. Rajah TT, Du N, Drews N, Cohn R: Genistein in the presence of 17betaestradiol inhibits proliferation of ERbeta breast cancer cells. Pharmacology 2009, 84(2):68-73.

40. Kim EJ, Shin HK, Park JH: Genistein inhibits insulin-like growth factor-I receptor signaling in HT-29 human colon cancer cells: a possible 
mechanism of the growth inhibitory effect of Genistein. Journal of Medicinal Food 2005, 8(4):431-438.

41. Sheng H, Shao J, Townsend CM, Evers BM: Phosphatidylinositol 3-kinase mediates proliferative signals in intestinal epithelial cells. Gut 2003, 52(10):1472-1478.

42. Medema RH, Kops GJ, Bos JL, Burgering BM: AFX-like Forkhead transcription factors mediate cell-cycle regulation by Ras and PKB through p27kip1. Nature 2000, 404(6779):782-787.

43. Eto I: Nutritional and chemopreventive anti-cancer agents up-regulate expression of p27Kip1, a cyclin-dependent kinase inhibitor, in mouse JB6 epidermal and human MCF7, MDA-MB-321 and AU565 breast cancer cells. Cancer Cell International 2006, 6:20.

44. Shen JC, Klein RD, Wei Q, Guan Y, Contois JH, Wang TT, Chang $S$, Hursting SD: Low-dose genistein induces cyclin-dependent kinase inhibitors and $\mathrm{G}(1)$ cell-cycle arrest in human prostate cancer cells. Molecular Carcinogenesis 2000, 29(2):92-102.

45. Jones JT, Akita RW, Sliwkowski MX: Binding specificities and affinities of EGF domains for ErbB receptors. FEBS Letters 1999, 447(2-3):227-231.

46. You H, Yamamoto K, Mak TW: Regulation of transactivation-independent proapoptotic activity of $\mathrm{p} 53$ by FOXO3a. Proceedings of the National Academy of Sciences of the United States of America 2006, 103(24):9051-9056.

47. Miyaguchi Y, Tsuchiya K, Sakamoto K: P53 negatively regulates the transcriptional activity of $\mathrm{FOXO3a}$ under oxidative stress. Cell Biology International 2009, 33(8):853-860

48. Park JH, Oh EJ, Choi YH, Kang CD, Kang HS, Kim DK, Kang Kl, Yoo MA: Synergistic effects of dexamethasone and genistein on the expression of Cdk inhibitor p21WAF1/CIP1 in human hepatocellular and colorectal carcinoma cells. International Journal of Oncology 2001, 18(5):997-1002.

49. Weber G, Shen F, Yang H, Prajda N, Li W: Amplification of signal transduction capacity and down-regulation by drugs. Advances in Enzyme Regulation 1999, 39:51-66.

50. Hwang JT, Ha J, Park OJ: Combination of 5-fluorouracil and genistein induces apoptosis synergistically in chemo-resistant cancer cells through the modulation of AMPK and COX-2 signaling pathways. Biochemical and Biophysical Research Communications 2005, 332(2):433-440.

\section{Pre-publication history}

The pre-publication history for this paper can be accessed here: http://www.biomedcentral.com/1471-2407/11/219/prepub

doi:10.1186/1471-2407-11-219

Cite this article as: Qi et al:: Genistein inhibits proliferation of colon cancer cells by attenuating a negative effect of epidermal growth factor on tumor suppressor FOXO3 activity. BMC Cancer 2011 11:219.

\section{Submit your next manuscript to BioMed Central and take full advantage of:}

- Convenient online submission

- Thorough peer review

- No space constraints or color figure charges

- Immediate publication on acceptance

- Inclusion in PubMed, CAS, Scopus and Google Scholar

- Research which is freely available for redistribution 